and interesting. The professors and lecturers of each department deal with the various subjects, which are illustrated by museum and laboratory demonstrations. An important section of the course is devoted to the prevention of malaria, a disease which alone produces more illness than any other. Instruction is also given on typhoid, dysentery and cholera, and on the various insects, worms and other animals which cause or transmit disease. Emphasis is laid on the precautions to be taken before leaving for the tropics, the kind of clothing to wear, the preservation of food and water, and many other problems which must be taken into consideration if a white man or woman is to lead a healthy life in the tropics.

The School feels that many of the firms employing young men and women abroad will realize the great value of such a course, both to themselves as well as to their employees. Those who are going to work on plantations and other estates, in mines, in engineering undertakings and other works abroad will find that they obtain useful information on how to keep fit. It is also of particular interest to missionary societies and other institutions which are sending people out on their behalf. In fact, men and women in all walks of life who are contemplating either a short or a long stay in hot climates will find this short course of instruction of the utmost value to them.

\section{THE 45TH CHEMISTS' EXHIBITION, LONDON}

The Chemists' Exhibition in London is one of the most important events of the year for the trade. The 45 th will be held on 21 st to 25 th September next in the handsome new hall of the Royal Horticultural Society, Westminster, S.W. The management, "The British and Colonial Pharmacist', is always pleased to welcome members of the drug trade from overseas and they are admitted on presentation of business cards. The exhibition-which in size and comprehensiveness is unequalled in the world-presents the latest products and attracts a very large attendance from chemists and druggists and all interested in the distribution of chemists' goods. Solely for the trade, it reflects the advance in the previous 12 months.

\title{
Current Topics
}

\section{Mandelic Acid and Ammonium Mandelate in the Treatment of Urinary Infections}

By H. E. HOLLING, м.в., м.sc. (Sheff.), M.R.C.P. (Lond.)

and

ROBERT PLATT, м.D. (Sheff.), F.R.c.P. (Lond.)

(Abstracted from the Lancet, Vol. I, 4th April, 1936, p. 769)

OF the 21 hospital cases treated, 13 were inpatients and the remainder outpatients. There were also 8 private patients, 3 of whom were in bed during the treatment.

Catheter specimens of urine were first examined to determine the nature of the infection, and pyelography (retrograde or intravenous) was performed where necessary, to exclude pyonephrosis, calculus, tuberculosis, etc.

The first few hospital patients were given mandelic acid, neutralized by sodium bicarbonate as described by Rosenheim. I Later the sodium salt was prescribed as follows:-

Sodium mandelate..

Syrup of orange

.. 50 grains.

Water to 1 ounce.

In water four times daily.

This was preceded by:-

Ammonium chloride

Liquid extract of liquorice

. 30 grains.

Water to 1 ounce.

Four times daily.

Fluid intake was restricted during treatment to two pints daily, unless thirst was complained of, when more fluid was allowed.

The acidity of the urine, which must attain a $\mathrm{pH}$ of 5.3 or less, was tested by the addition of five drops of methyl-red solution to $2 \mathrm{c.cm}$. of urine. This gives a bright pink colour if the urinary acidity is satisfactory, but an orange or yellow colour if it is too alkaline. The amount of ammonium chloride administered was then increased or reduced accordingly. As a rule, a satisfactory acidity can be produced with about half the dose prescribed above. In private patients the ammonium chloride was given in 1.0 gramme capsules (4 to 8 daily).

Finally, 4 cases were treated by ammonium mandelate (see later).

Specimens of urine were examined at two-day intervals where possible. When the deposit (examined as a wet film) showed only a few leucocytes and no bacilli, cultures were again made from catheter specimens.

\section{Comment}

The results of treatment are set out in the accompanying table, and it will be seen that in every uncomplicated case of acute or chronic pyelonephritis the urine was rendered sterile by mandelic acid treatment in from 2 to 21 days in 24 out of 29 cases. [The failures are reported in detail in the paper; they were all complicated cases with some underlying condition, such as tuberculosis and prostatic calculi or urinary infection was associated with some other condition, such as pernicious anæmia.]

During treatment a few casts and a trace of albumin occasionally occur in the urine. The treatment is obviously unsuitable in the presence of renal insufficiency because badly damaged kidneys cannot excrete a sufficiently acid urine or a sufficient concentration of mandelic acid. Nevertheless the presence of nephritis in an earlier stage does not appear to be a contraindication, as is shown by the two cases in which renal œdema was present. The superimposed urinary infection was cleared up in each without any apparent change in the course of the nephritis. In a case of hypertension without renal insufficiency the course of the disease also was unaffected, except favourably by the removal of the symptoms of urinary infection.

In two cases relapse occurred; one was again successfully treated. Case 18 had previously had scarlatinal nephritis; intravenous pyelography showed slight stenosis of the right ureter and a ureteric catheter was therefore passed and kept in position for three days during mandelic acid treatment. Case 20 had had mandelic acid treatment at home once before and relapsed; she had a history of having had 'cystitis' at the age of 13 years. In cases $7,13,19,22,23$ and 25 a recent acute pyelonephritis had been controlled by alkaline treatment, but a heavy infection still remained. Cases 10 and 14 were treated with mandelic acid in the acute stage. 
SUMMARY OF CASES

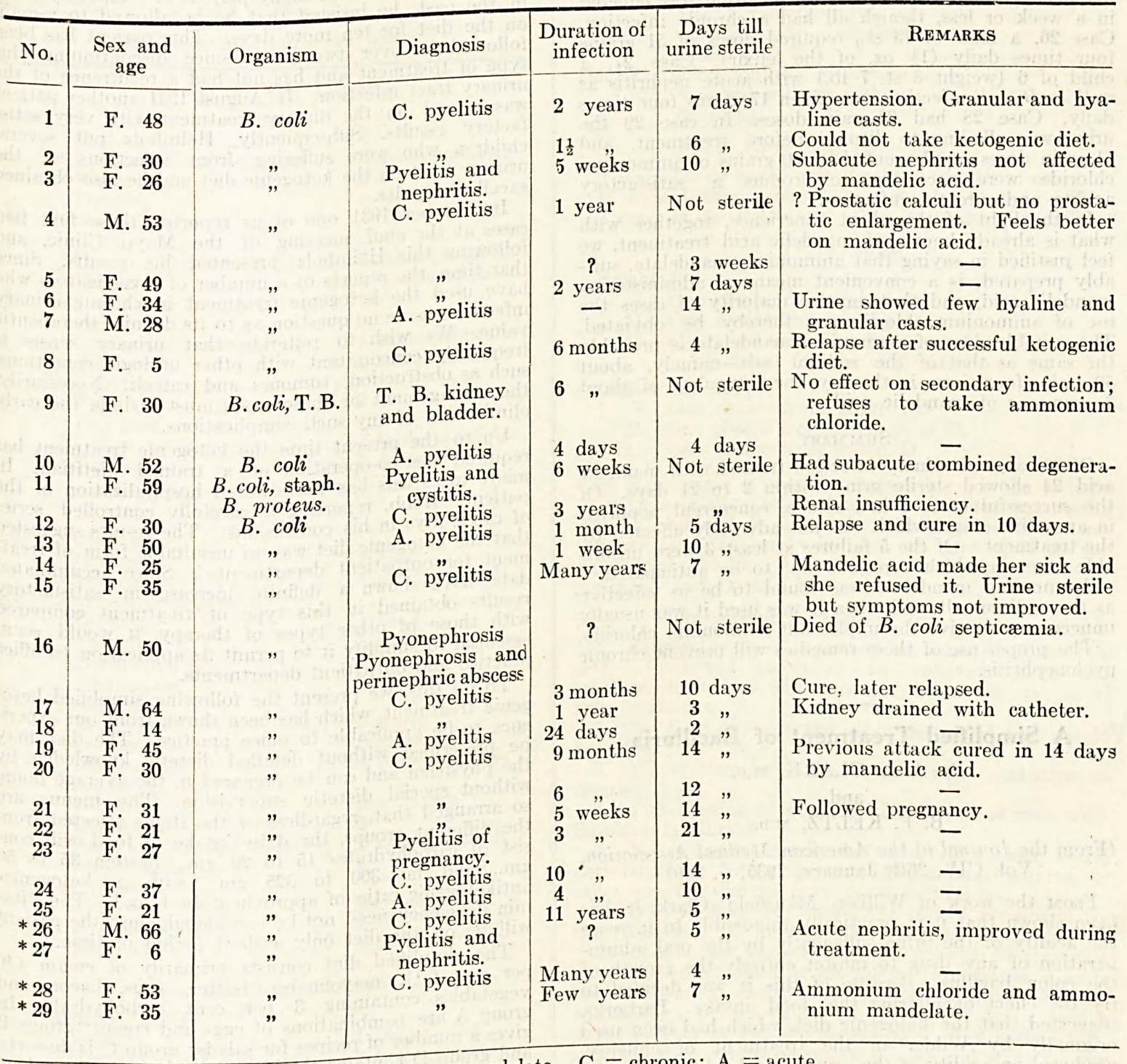

* Treated with ammonium mandelate. C. $=$ chronic; A. $=$ acute.

\section{AMmonium MaNDELATE}

The only disadvantage of mandelic acid treatment as o far practised is the necessity of giving two somewhat unpleasant medicaments, one followed closely by the other, four times in the day. The ammonium chloride is particularly nauseous to some patients and man in actually cause vomiting, and even when it is given capsule form there may be an unpleasant after-taste.

Mandelic acid has to be given as a salt because the acid itself is a gastric irritant. The ammonium chloride is given to acidify the urine so that a proportion of the mandelate administered is excreted as mandelic acid.

To obviate these disadvantages if possible, the British Drug salt of for of mandelic acid, and we are inder clinical trial. for placing stocks at our disposal for clinical trial. They state that ammonium mandelate, form and they scopic, cannot be supplied in tablet form an which have therefore made it up as an elixir, 1 oz. Of which ( 2 grammes) of mandelic acid.

Salts such as ammonium chloride act as acids in the body owing to the ammonium radicle being converted into urea, and leaving the acid radicle to be excreted. Ammonium mandelate should be weaker in its action than ammonium chloride, but on the other hand the use of ammonium mandelate dispenses with the necessity of giving the sodium salt, and so saves the addition of an unnecessary alkali. Based on molecular weights, 3.0 grammes of sodium mandelate plus 1.0 gramme of ammonium chloride (approximately the usual doses) should be roughly equivalent to the effect of 3.0 grammes of ammonium mandelate administered by itself.

It seems likely that, provided the urine can be sufficiently acidified by ammonium mandelate alone, the bacteriostatic effect of the mandelic acid radicle will be as good as when the sodium salt is used. We therefore tried the acidifying effect of the elixir of ammonium mandelate on ourselves (it is not particularly unpleasant to take) and found that doses of 34 grains of ammonium mandelate four times daily produced a satisfactory urinary acidity ( $\mathrm{pH}$ 5.3) within an hour or two, but this degree of acidity was not invariably maintained throughout the day. As we are both of about average weight (10 st. $2 \mathrm{lb}$. and $10 \mathrm{st}$. $9 \mathrm{lb}$.) we concluded that somewhat larger doses should generally be given for the treatment of patients. 
Four patients were treated with ammonium mandelate, and in all four a sterile urine was effected in a week or less, though all had a chronic infection. Case 26, a man of 13 st., required doses of 51 grains four times daily ( $1 \frac{1}{2} \mathrm{oz}$. of the elixir). Case 27, a child of 6 (weight 3 st. $7 \mathrm{lb}$.) with acute nephritis as well as $B$. coli infection, was given 17 grains four times daily. Case 28 had 34-grain doses. In case 29 the urine was alkaline to litmus before treatment, and 51-grain doses supplemented by 30 grains of ammonium chloride were necessary to produce a satisfactory acidity and cure the infection.

In the light of this short experience, together with what is already known of mandelic acid treatment, we feel justified in saying that ammonium mandelate, suitably prepared, is a convenient means of administering mandelic acid, and that in the majority of cases the use of ammonium chloride can thereby be obviated. The suitable dose of ammonium mandelate is probably the same as that of the sodium salt-namely, about 50 grains four times in the day, the equivalent of about 3 grammes of mandelic acid.

\section{SUMMARY}

Of 29 cases of urinary infection treated with mandelic acid 24 showed sterile urine within 2 to 21 days. Of the successful cases 2 had also a concurrent nophritis in an active stage, which was not adversely affected by the treatment. Of the 5 failures at least 3 were unsuitable cases in which cure was not to be anticipated.

Ammonium mandelate was found to be as effective as the sodium salt, and when it was used it was usually unnecessary to give the unpleasant ammonium chloride.

The proper use of these remedies will prevent chronic pyelonephritis.

\section{A Simplified Treatment of Bacilluria}

By A. L. CLARK, m.D.

and

B. F. KELTZ, M.D.

(From the Journal of the American Medical Association, Vol. CIV, 26th January, 1935, p. 289)

From the work of William Mansfield Clark it has been shown that it is practically impossible to increase the acidity of the urine sufficiently by the oral administration of any drug to inhibit entirely the growth of the colon bacillus. Because of this it was decided to try the effect of altering the food intake. Barborka suggested that the ketogenic diet, which had been used originally by Wilder in the treatment of epilepsy, produced an acidity of the urine considerably above the normal. Previously, Johnson had placed several patients with a bacillary infection of the urinary tract on the ketogenic diet. He noted some improvement in their condition, but the patients were too ill to allow a thorough test of the treatment. About this time Helmholz had noted that the urine of a patient on the ketogenic diet for the treatment of epilepsy remained clear and apparently sterile, although it had been voided into an unsterile vessel and allowed to stand for a number of days.

To a patient who had returned to the Mayo Clinic a number of times for treatment of a persistent bacillary infection of the urinary tract belongs the real credit for making the ketogenic treatment available to the other sufferers of this ailment. During his fourth trip to the clinic in fourteen months he announced that he would stay until his condition was entirely relieved. At this visit, as before, many different types of treatment, both local and oral, were applied, with only temporary periods of improvement. The culture of the urine showed the infecting organism to be the colon bacillus. On 21st July, 1931, the patient was placed on the ketogenic diet. In five days his symptoms of burning, frequency and urgency of urination were relieved. In twelve days a culture of the urine revealed the absence of the colon bacillus. Refusing to believe in his good fortune, because of his many periods of temporary relief in the past, he insisted that he be allowed to remain on the diet for ten more days. This patient has been followed for over two years since discontinuing this type of treatment and has not had a recurrence of the urinary tract infection. In August 1931 another patient was placed on the dietary treatment with very satisfactory results. Subsequently, Helmholz put several children who were suffering from infections of the urinary tract on the ketogenic diet and he also obtained excellent results.

In October 1931 one of us reported these first two cases at the staff meeting of the Mayo Clinic, and following this Helmholz presented his results. Since that time, the reports of a number of investigators who have used the ketogenic treatment in chronic urinary infections leave no question as to its definite therapeutic value. We wish to reiterate that urinary sepsis is frequently concomitant with other urologic conditions, such as obstruction, tumours and calculi. Necessarily, the management of these cases must include the early elimination of any such complications.

Up to the present time the ketogenic treatment has required the co-operation of a trained dietitian. In many cases this has necessitated hospitalization of the patient. Robb, reporting a carefully controlled series of cases, says in his conclusions: "The results suggested that the ketogenic diet was an unsuitable form of treatment for outpatient departments'. Since accumulated data have shown a definite increase in satisfactory results obtained in this type of treatment compared with those of other types of therapy, it would seem essential to simplify it to permit its application to office practice and outpatient departments.

To do this, we present the following simplified ketogenic treatment, which has been shown from our experience to be applicable to office practice. The diet may be prescribed without detailed dietetic knowledge by the physician and can be prepared in the average home without special dietetic supervision. The menus are so arranged that, regardless of the items selected from the different groups, the daily intake of food will consist of carbohydrates 15 to $20 \mathrm{gm}$., protein 35 to 50 gm., and fat 300 to 325 gm., with a ketogenicantiketogenic ratio of approximately 4 to 1 . The vitamin deficiency need not be considered, since the patient will be on the diet only a short period of time.

The simplified diet consists primarily of cream (40 per cent fat), mayonnaise, butter, eggs, bacon and vegetables containing 3 per cent carbohydrate. In group A are combinations of eggs and cream; group B gives a number of recipes for salads; group $\mathrm{C}$ is desserts, and group $\mathrm{D}$ contains the beverages that may be taken. The various items in each group have approximately the same carbohydrate, protein and fat content. The daily menu instructs the patient from which group selections are to be made for each meal.

How is the ketogenic diet effective in eradicating urinary sepsis? Two conditions are necessary. Sufficient concentration of ketone bodies must be present in the urine coincidental with an acidity of the urine of $\mathrm{pH} 5.2$ or less if satisfactory results are to be obtained. Fuller has shown that lævo-rotatory beta-oxybutyric acid is the ketone body producing the greatest bacteriostatic effect. Helmholz and Osterberg were able to demonstrate the bactericidal effect of urine with a $\mathrm{pH}$ of 5.2 and a beta-oxybutyric acid content of 0.5 per cent. Recent work by Clark, Moore and Harrell, however, indicates that at a $\mathrm{pH}$ of 5.0 and a beta-oxybutyric acid content of the urine up to 1.5 per cent the effect of the urine is not sufficiently bactericidal to inhibit entirely the growth of the organisms. As the average beta-oxybutyric acid content of the urine of an adult patient on the ketogenic diet will not exceed a concentration of 1.2 per cent and the average acidity of the urine will not be greater than $\mathrm{pH} 5.0$, it is probable that the action of the ketogenic treatment is one of bacteriostasis. It is important that this bacteriostatic effect be continuous and be maintained as uniformly maximum as possible during the entire twenty-four 
hours. Only in this way will the last organism be washed from the urinary tract.

The simplified ketogenic diet

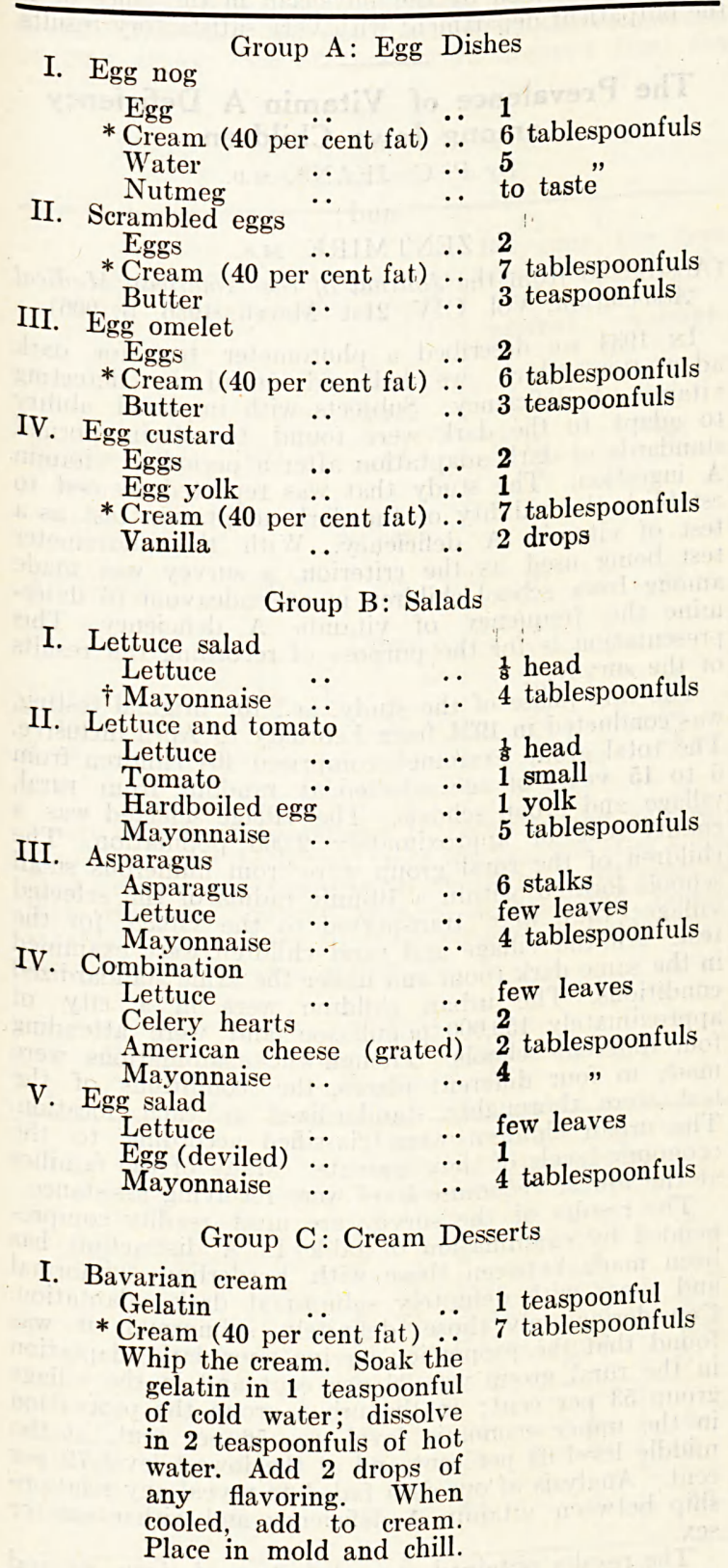

* It is of the utmost importance to use extra thick cream containing at least 40 per cent fat. The average whipping cream is only about 32 per cent fat.

$\dagger$ Recipe for mayonnaise:

$\begin{array}{llll}\text { Egg .. } & \ldots & \ldots & 1 \\ \text { Vinegar } & \ldots & \ldots & 2 \text { tablespoonfuls } \\ \text { Salad oil } & \ldots & \ldots & 1 \text { pint } \\ \text { Salt .. } & \ldots & \ldots & 2 \text { teaspoonfuls } \\ \text { Mustard } & \ldots & \ldots & 1 \text { teaspoonful } \\ \text { Pepper } & \ldots & \ldots & \text { few grains }\end{array}$

Have ingredients cold. Beat egg until stiff. Add dry ingredients. Add oil drop by drop, beating constantly. Thin with vinegar to the desired consistency.
II. Gelatin

Make plain gelatin as in $\mathrm{I}$. Use 7 tablespoonfuls of unsweetened whipped cream over it,

III. 7 tablespoonfuls of cream, whipped with or without flavoring.

\section{Group D: Beverages}

Tea, coffee or water with 4 tablespoonfuls of cream. If desired, this amount of cream may be used with

2 cups of the beverage. Use no sugar or milk.

Daily menu

Breakfast

I. One choice from group A

II. One choice from group D.

III. 8 slices of thin crisp bacon or 4 tablespoonfuls of cream (40 per cent fat).

\section{Dinner and supper}

I. One choice from group B.

II. One choice from group $\mathrm{A}$ or $\mathrm{C}$.

III. One choice from group D.

In some cases it may be impossible for the patient to have specially prepared menus. Satisfactory results will be obtained if one and one-half pints of cream (40 per cent fat) and six eggs are prescribed as the daily food intake. The recipes and suggestions in groups A and D may be used.

\section{Important instructions to patient}

1. Satisfactory results cannot be obtained unless this diet is followed absolutely as outlined. Even the smallest deviations will ruin the chance for success of this treatment.

2. No food or beverage other than that listed is to be taken.

3. Water may be taken in moderate quantities as desired.

4. The chewing of gum or tobacco is not permitted. Smoking is allowed.

5. No cathartics are to be used other than liquid petrolatum or bitter cascara. Magnesium magma or other sweet cathartics may cause failures.

6. Do not take any medicines unless prescribed by the physician. It may conflict with the diet.

Experience has shown that the patient who quickly develops and maintains an intense ketosis is greatly benefited in a short time. Ketosis should develop within three to five days. At the end of ten or twelve days, whether or not the results have been satisfactory, a mixed diet should be resumed. Several short courses of the dietary treatment are preferable to one long course. Certain patients will put through the ketone products in the urine much more quickly than others. To maintain a continuous ketonuria it may be necessary to space the intake of fat more evenly. This may be done by supplementary feedings of cream (40 per cent fat) between meals, especially between the evening meal and breakfast. During the treatment the physician should not be alarmed if the patient is nauseated. It may cause the patient to miss one or more meals without interfering with the desired results. Experience has shown that normal exercise and activity will lessen anorexia. Only the normal fluid intake should. be prescribed. To force fluids will lessen the bacteriostatic effect by diluting the ketone bodies in the urine.

\section{DAILY TESTS}

Evidence of ketosis is based on the test for diacetic acid in the urine. If it is present, equal parts of a 10 per cent aqueous solution of ferric chloride and the patient's urine give a port wine color. It must be remembered that a patient who is taking acetylsalicylic acid will give a false positive test. The tests for diacetic acid and acidity of the urine should be made daily. Herrold suggests a most useful procedure for an approximate measure of the acidity, which may be 
quickly and easily done in the office. To 20 drops of the patient's urine, one drop of 0.04 per cent solution of chlorphenol red is added. If the color of the urine remains the same, it is safe to assume that the acidity is $\mathrm{pH} 5.2$ or less. After the addition of the indicator, if the solution becomes faintly pink or red, the acidity is above $\mathrm{pH} 5.2$ and indicates that further measures for acidification of the urine will be necessary to obtain satisfactory results.

A stain of the urine sediment should be made every other day. After three tests have shown that the bacillus is apparently no longer present in the urine, the treatment may be discontinued. The final test, of course, is whether or not the bacillus is found in the urine after the patient has returned to a general mixed diet and the ketone bodies have disappeared from the urine. When one can follow the progress of the patient conveniently, microscopic examinations of the urine will eliminate the need for cultures as the final test of a satisfactory result.

\section{Drugs}

In prescribing the simplified ketogenic diet, we have found it advisable to give no oral medication until ketone bodies have appeared in the urine. At that time, if the acidity of the urine is above $\mathrm{pH} 5.2$, it may be advisable to give ammonium chloride orally to increase its acidity. Ammonium chloride 12 drachms $(47 \mathrm{gm}$.) in 8 ounces $(240$ c.c.) of water makes a solution of which 2 fluid drachms (8 c.c.) in a glass of water may be given after each meal and at bedtime. This medication may upset the gastro-intestinal tract, in which case 15 grains ( $1 \mathrm{gm}$.) of the drug is given every two hours for six doses. The 15 grains is prepared in the form of two enteric coated tablets, each of $7 \frac{1}{2}$ grains $(0.5 \mathrm{gm}$.)

In some cases tests will indicate that sufficient acidity has developed but that the percentage of ketone bodies in the urine is insufficient to produce the necessary bacteriostatic action. In such an instance, the oral administration of methenamine may increase the bacteriostatic power of the urine to a point at which the organism will be eliminated.

\section{LOCAL TREATMENT}

Hydrostatic lavage of the bladder with $1: 2,000$ solution of acetic acid or $1: 8,000$ solution of potassium permanganate may be instituted; but excellent results have been obtained without lavage, particularly in women. It should be remembered that the mechanical and chemical irritation of the catheter and lavage may offset the relief afforded by the ketogenic treatment. In male patients, a gentle massage of the prostate gland every second day is given to eliminate this as a focus of infection. In a number of cases in which there are resistant or recurring infections, urethroscopy may reveal dilated prostatic ducts leading from small chronic abscesses. As organisms from these foci may constantly reinfect the urine, drainage from such regions should be obtained by cystoscopically enlarging these ducts, as described by Thompson. In women, urethral cysts and small infected urethral glands should receive careful attention.

Trequently the coccic type of infection may be associated with the bacillary type. In these cases a short course of neoarsphenamine may be helpful; an intravenous injection of $0.3 \mathrm{gm}$. is given every five days for from four to six doses.

In prescribing the ketogenic treatment it must be remembered that the bacteriostatic agent must pass through the kidney. Poor renal function, particularly if unilateral, is a contra-indication for this type of treatment. In carefully observed cases it has been found that the ketone bodies will be largely excreted through the kidney with good function. There are two groups of cases for which we have no explanation as to the possible reasons for unsatisfactory results. One group will not develop a ketonuria, while in the second group the $\mathrm{pH}$ of the urine remains high, although large doses of some acidifying agent are administered.
SUMMARY

Applied in short courses, the simplified ketogenic treatment of bacillary infections of the urinary tract may be prescribed by the physician in the office or in the outpatient department with very satisfactory results.

\section{The Prevalence of Vitamin A Deficiency among Iowa Children}

By P. C. JEANS, M.D.

and

\section{Z. ZENTMIRE, M.s.}

(Abstracted from the Journal of the American Medical Association, Vol. CIV, 21st March, 1936, p. 996)

IN 1934 we described a photometer test for dark adaptation which we believed useful in detecting vitamin A deficiency. Subjects with impaired ability to adapt to the dark were found to attain normal standards of dark adaptation after a period of vitamin A ingestion. The study that was reported seemed to establish the validity of the dark adaptation test as a test of vitamin A deficiency. With the photometer test being used as the criterion, a survey was made among Iowa school children in an endeavour to determine the frequency of vitamin A deficiency. This presentation is for the purpose of recording the results of the survey.

The first phase of the study, i.e., the original testing, was conducted in 1934 from February to April inclusive. The total group examined comprised 404 children from 6 to 15 years of age selected at random from rural, village and urban schools. The village selected was a county seat of approximately 2,000 population. The children of the rural group were from numerous small schools located within a 10-mile radius of the selected village; they were transported to the village for the test. All the village and rural children were examined in the same dark room and under the same standardized conditions. The urban children were in a city of approximately 150,000 population and were attending four different schools. Though the examinations were made in four different places, the conditions of the test were thoroughly standardized in each location. The urban children were classified according to the economic levels of their parents. Many of the families at the lowest economic level were receiving assistance.

The results of the survey are most readily comprehended by examination of table I. A distinction has been made between those with borderline subnormal and those with definitely subnormal dark adaptation. Considering only those definitely subnormal, it was found that the proportion having poor dark adaptation in the rural group was 26 per cent and in the village group 53 per cent; in the urban group the proportion in the upper economic level was 56 per cent, at the middle level 63 per cent and at the lowest level 79 per cent. Analysis of our data failed to reveal any relationship between vitamin A deficiency and either age or sex.

The results obtained were definite and clean cut and no obvious reason was apparent for doubting them. However, the proportion of subnormal results was so unexpectedly high that it was thought best to continue the study by re-examining some of the children after a period of vitamin A ingestion. An attempt was made to include in this second phase of the study all the rural and village children who had had borderline or definitely subnormal results at the first testing. For a period of several weeks either halibut liver oil or carotene in oil was administered each school day by the teachers. Those who did not show normal dark adaptation by the time school closed were given one of these products to use at home and at the same time we started bringing the children in small groups into the Children's Hospital and retaining them until normal dark adaptation was attained. Of the total group of ninety-nine rural and village children whose tests had shown abnormal results, all except twelve continued under 
observation. The reasons for these twelve exceptions were illness, rem lack of co-operation. These twelve children did not receive a second test. Nine other children were observed and tested further but did not continue to the completion of their study. Six of these were dropped from the

TABle I

Survey of Iowa school children as regards dark adaptation

\begin{tabular}{c|c|c|c|c}
\hline $\begin{array}{c}\text { Economic } \\
\text { level }\end{array}$ & $\begin{array}{c}\text { Number } \\
\text { examined }\end{array}$ & $\begin{array}{c}\text { Per cent } \\
\text { normal }\end{array}$ & $\begin{array}{c}\text { Pent } \\
\text { borderline } \\
\text { sub- } \\
\text { normal }\end{array}$ & $\begin{array}{c}\text { Per cent } \\
\text { definitely } \\
\text { sub- } \\
\text { normal }\end{array}$ \\
\hline
\end{tabular}

\begin{tabular}{|c|c|c|c|c|}
\hline $\begin{array}{l}\text { Middle to } \\
\text { low. }\end{array}$ & 100 & 64 & 10 & 26 \\
\hline & & lage & & \\
\hline All levels & 102 & $\begin{array}{l}37 \\
\text { rban }\end{array}$ & 10 & 53 \\
\hline $\begin{array}{ll}\text { Upper } & \\
\text { Middle } & \text {. } \\
\text { Low } & \ldots\end{array}$ & $\begin{array}{l}70 \\
70 \\
62\end{array}$ & $\begin{array}{l}34 \\
27 \\
11\end{array}$ & $\begin{array}{l}10 \\
10 \\
10\end{array}$ & $\begin{array}{l}56 \\
63 \\
79\end{array}$ \\
\hline
\end{tabular}

group because they refused to come to the hospital; the others were discharged from the hospital after a few days because of exigencies in the home. All nine of these children, however, showed definite and unmistakable improvement in dark adaptation before they went from under observation.

TABLE II

Results of retesting after administration of vitamin $A$

\begin{tabular}{|c|c|c|c|c|c|}
\hline \multirow[b]{2}{*}{ School } & \multirow[b]{2}{*}{$\begin{array}{l}\text { Number } \\
\text { subnormal } \\
\text { first test }\end{array}$} & \multicolumn{4}{|c|}{$\begin{array}{l}\text { AFTER ADMINISTRATION OF } \\
\text { VITAMIN A OR CAROTENE }\end{array}$} \\
\hline & & 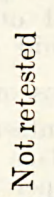 & 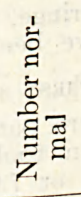 & 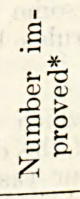 & 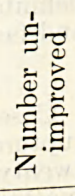 \\
\hline $\begin{array}{l}\text { Rural } \\
\text { Village }\end{array}$ & $\begin{array}{l}36 \\
63\end{array}$ & $\begin{array}{l}9 \\
3\end{array}$ & $\begin{array}{l}24 \\
51\end{array}$ & $\begin{array}{l}3 \\
6\end{array}$ & $\begin{array}{l}0 \\
3\end{array}$ \\
\hline Totals & 99 & 12 & 75 & 9 & $3 \dagger$ \\
\hline
\end{tabular}

* Only a brief period of observation permitted.

$\uparrow$ After approximately six weeks of treatment.

The data presented in table II show that of the seventy-eight children in table II sher observation only three failed to who contion. These three failed to attain normal dark from three to six three remained in the hospital to keep them longer. Car and it was impracticamination failed to reveal any abnormality that would account for the poor dark adaptation. It would be only conjecture to state that a protracted period of vitamin A deficiency may have produced period of vitamind that possibly a longer period a refractory state andion would have longer period of vitamin A ingestion would hoted that the children about improvement. We have in the hospital to attain no required the longest sta well as these three to attain normal dark adaptation, as well as the did not like foods rich in vitamin A or carotene. If these three children are considered to represent exceptions to the rule that the dark adaptation test is a test of vitamin A deficiency, the test is still more than 95 per cent efficient when applied in a large scale survey.

The halibut liver oil and carotene in oil were administered in dosages computed to be approximately equivalent to the vitamin A content of 3 teaspoonfuls of cod-liver oil daily. Of the children whose dark adaptation was subnormal, the great majority attained normal adaptation within a period of a month after starting ingestion of vitamin A. At the dosage levels used, no difference was detected between the effectiveness of vitamin $A$ and of carotene.

The second phase of this study gave evidence in addition to that in our former report that the test described is useful in detecting vitamin A deficiency. Also the conclusion seems permissible that the test may be used in large scale surveys with small chance of error, even if expert medical consultation is not employed. It is indicated also that vitamin A deficiency is much more prevalent than usually has been assumed.

Two other studies of the prevalence of vitamin A deficiency among school children have been found in the literature. Widmark and Svensson examined approximately 1,200 children from all economic and social strata of the manufacturing and seaport city of Malmo, Sweden, with a population of 120,000 . They used the photometer test of Edmund, which consists of a single test of vision immediately on entering a dark room and without a period of adaptation. Only nine children were thought to have vitamin $A$ deficiency. Frandsen found slight hemeralopia in forty-six of sixtyfive apparently healthy school children of Copenhagen; latent hemeralopia was present in seventy of seventytwo children examined as private patients for eye complaints. Improvement or cure was produced by the administration of cod-liver oil for several weeks or months. The degree of night blindness was determined by the ability to distinguish letters of varying shades from black to faintest gray on a white background, in a light of constant dimness, after an adaptation period of from five to ten minutes.

\section{SUMMARY}

Using a test for ability to adapt to the dark as the means for detecting vitamin A adequacy, we found that 26 per cent of a rural group and 53 per cent of a village group of Iowa children presented evidence of vitamin A deficiency; in an urban group the proportion for the higher economic level was 56 per cent, for a middle level 63 per cent and for a low economic level 79 per cent. Of the seventy-eight village and rural children who were deficient in vitamin $A$ and who continued under observation, all except three developed normal dark adaptation after a period of vitamin A or carotene ingestion.

\section{Acute Otitis Media: Its Treatment with Results}

By A. CAMPBELL, M.B., F.R.C.S.Ed.

(From the British Medical Journal, Vol. I, 18th April, 1936, p. 788)

During the course of a common cold, an influenza, or other febrile disease a patient develops an acute inflammation of the middle ear. So long as the otitis remains catarrhal-that is to say, an inflammation without the formation of pus within the middle ear-the treatment is more or less the same: drops to relieve the pain, rest in bed, calomel, heat applied to the ear as radiant heat or in the form of fomentations. Drops to relieve pain may be misleading, as with the cessation of pain we may consider the patient is improving, whereas the contrary is often the case. However, there is no doubt that a considerable proportion of patients respond to the treatment and recover without any further complication.

On the other hand, in a large proportion catarrhal otitis becomes suppurative. There is increasing pain, 
deafness, tinnitus, vertigo, a rise of temperature-particularly in children-and perhaps even tenderness over the mastoid process. It is now time to consider the advisability of a paracentesis. The drum is usually red and bulging. The bulging alone is a sufficient indication for a paracentesis in the absence of any of the symptoms which have already been mentioned, but usually it is associated with one or more signs or symptoms, such as pain, deafness, and frequently tenderness over the mastoid.

\section{Technique of Paracentesis}

Paracentesis is invariably done in a nursing home under a general anæsthetic such as ethyl chloride. After the skin of the ear and auditory canal is cleaned and painted with iodine the anæsthetic is commenced and an incision is made from below upwards in the posterior half of the drum, care being taken to avoid touching the inner wall of the tympanic cavity with the point of the knife. Pus or serum, sometimes accompanied by gas, escapes. A wick of gauze is introduced as far as the drum, and should be left in till the following morning, when it may be removed.

The discharge may be copious at once, or it may take thirty-six to forty-eight hours before it is free. The discharges are mopped up with sterile wool for fortyeight hours, and then, if copious, the ear is irrigated fcur-hourly, six-hourly, or thrice daily, according to the quantity of the discharge. The more copious it is the more frequently is the ear irrigated and dried. Irrigation, which may be carried out with a Higginson syringe fitted with a glass nozzle, should be gentle. It is comforting to the patient, and is tolerated by even the most nervous children. Force should not be used in irrigating.

The essential points in after-treatment are therefore frequent syringing followed by thorough drying of the auditory canal, so that neither debris nor pus may impede the free drainage from the middle ear. Radiant heat is applied to the ear thrice daily for about twenty minutes at a time. The mastoid area may be fomented if there is pain or tenderness in this region. Such symptoms persisting for a day or two after paracentesis do not mean that there is a mastoiditis which will necessitate operation. In the great majority of cases the patient recovers without further surgical treatment. Rest in bed for at least a week is essential after a paracentesis, by which time the temperature in children has usually become normal. Adults have little or no fever with an uncomplicated acute otitis media.

\section{COMPLICATIONS AND AFTER-CARE}

The most serious complication in the early stages of an acute otitis is meningitis, but fortunately this is rare. It is important to watch the temperature and to look for early signs of meningitis if it remains elevated. No rule can be set down in this matter, as cases vary so much in different seasons and years.

In the uncomplicated case the discharge becomes gradually less in about a week or ten days, and usually ceases in about sixteen days. After the discharge ceases, which coincides with the closure of the perforation or incision in the drum, the hearing is still impaired.

Politzerization daily or thrice weekly will restore the hearing to normal in a fortnight, or in all about thirty days from the commencement of the otitis. This is the course in the average cases. The patient remains in the nursing home for about ten days, and then is treated daily in the consulting room till the discharge ceases, and thereafter twice or thrice weekly till the hearing is restored to normal. In short, the treatment may be summarized as follows: paracentesis, syringe, dry, politzerize, dry, powder.

\section{VALUE OF SYRINGING}

The treatment which has been described is one I have used for the last fourteen years without variation. A form of treatment frequently described as the 'dry treatment'-that is to say, never irrigating, but relying on mopping the canal followed by the instillation of drops-has not been used in this series. If an ear is not syringed it soon collects debris and pus sufficient to interfere with free drainage.

It is idle to say syringing may cause secondary infection of the middle-ear cavity. Assuming the paracentesis and the after-treatment is done aseptically, then we can at worst only drive the same bacteria into the middle ear as came out of it. But we must not overlook the fact that the mucous membrane of the middle ear is acutely inflamed, and little or no cavity exists because of the odema; the possibility of driving bacteria back into this almost non-existent cavity is therefore extremely remote.

The use of drops, such as alcohol, magnesium sulphate, glycerin, hydrogen peroxide, picric acid, etc., seems to me to be useless. They cannot penetrate the middle-ear cavity, as the œdematous mucous membrane will not permit this. Moreover, if strong antiseptics such as alcohol, picric acid, etc., did penetrate the middle-ear cleft they would paralyse the ciliated mucous membrane for some nours, and the useful purpose it serves of propelling the discharge onward would be suspended, at least temporarily.

Drops are useful in certain stages; if a conical perforation develops it is often benefited by boric acid and alcohol drops, but then there is no danger of the drops reaching the tympanic cavity. It is often said that syringing drives the bacteria into the mastoid process, but the mastoid cells are in an active state of inflammation in every case of acute otitis media. This is well demonstrated in the early stages by $x$-rays, in which the cells show up as cloudy compared with the normal mastoid. Traumatic perforations, however, should not be syringed unless they reach the stage of profuse discharge; then they may be treated as a paracentesis case.

\section{THE DRY METHOD}

The method of mopping up the discharge has been described as the dry method, but I believe the method which I have described is the true dry method. The only wet part of the treatment is the irrigation; then the canal is dried thoroughly. After the patient leaves the nursing home the ear is syringed daily, dried, politzerized so as to drive away any secretions out of the tympanic cavity, dried again, and finally powdered with boric acid.

A study of the literature on the subject of the treatment of acute otitis has not presented anything very definite; some syringe, and others do not; no hardand-fast rules have been laid down by either side.

First SERIEs of CASES

Cases which were paracentesized before spontaneous rupture of the drum took place numbered 339; of these, twenty-four cases, or 7.06 per cent, required a simple mastoid operation. One of the paracentesis patients died as a result of pneumococcal meningitis without macroscopic evidence of involvement of the mastoid cells; it seemed to be a fulminating type.

The healing of the perforation took on an average sixteen and a half days, and the return to normal hearing averaged thirty days from the date of paracentesis. The hearing result was noted in only 161 cases, as many small children could not be tested, and others with previous hearing defects could only be estimated. Of the 161 patients all were satisfied that no defect in hearing was left after healing was complete. Age and sex were noted in all cases, but they have no bearing on the subject, except to demonstrate that the majority were children.

\section{SECOND SERIES OF CASES}

Cases which were paracentesized after the discharge had commenced, owing to pain, elevation of temperature, mastoid tenderness, etc., numbered 126 . It is surprising how frequently on incising the drum in such cases pus escapes under pressure. Of this series twentytwo, or 17.4 per cent, required a simple mastoid operation. There were a few cases where the operation was performed two or three days after paracentesis, and I think these should be left out of this calculation, as 
they probably had a mastoiditis when the paracentesis was done. The more correct percentage, therefore, would be between 14 and 15 . There was one death in this series, dueen 14 and 15 . Thered by a hæmolytic streptococcus, without macroscopic involvement of the mastoid.

A comparison of the first and second series demonstrates that early paracentesis, before spontaneous rupture takes place, is the best form of treatment. Quite apart from an early paracentesis there are other factors which inflan early paracentes the chief of these factors which influence the disease, the chief of these being, I believe, the virulence of the infection and the resistance of the patient. In certain years the disease is mild, in others it is exceptionally virulent, and liable to give rise to complications.

The most frequent causes of otitis media in these cases were the common cold and influenza, followed in order by tonsils and adenoids, scarlet fever, and measles. Nine cases followed operation on the nose, of which four required mastoid operations.

\section{Cases REQUiRing OPERATION}

One hundred and six patients were operated on by the Schwartze method, which is commonly known as the simple mastoid operation, with preservation of the drum and return of cases to normal. As a routine method the mastoid antrum, the lateral sinus wall, and the dura of the middle foss las was explored and removed in most cases. Except in a few isolated instances the ro that the possibility of overlooked infected cells, a perisinusitis, or extradural abscess was minimized.

Twenty-two, or 20 per cent, of these patients had been paracentesized before spontaneous rupture; the balance of 80 per cent all or on 80 per cent were either not parad occurred. These figures show the importance of early paracentesis; 93 per cent paracentesis before rupture, with return of hearing to normal within a month.

After the Schwartze operation is completed an attempt is made to syringe saline through the aditus so that it comes out of the perforation and into the external it comes out of the perforation and not to force the liquid throu in. Care must be taken ity is then filled up with a packing with absolute alcohol, dried, iodoform gauze packexternal canal is plugged with narrow iodoform gauze, so that no narrowing of the canal is allowed to take place. The nor four days when the packing is removed, which is always a painful when the packing is removed, which is always a till the process. Fresh gauze is reintroduced daily till the cavity heals by granulation. The perforation usually heals in fow cavity is allowed in a few days, and from then on the cavity to bring the skin edges together is sometimes necessary. Event the skin edges together is sometining to normal. Thentually politzerization will restore hearing to normal. of acute mastoiditis.

\section{RESUlts OF OPERATION}

In the 106 patients operated on the ages varied from 6 months to 60 years; 48 per cent were under the age of 12 . The cases, of which fift resur were noted as good, and five as in good, and five as moderate. It must be remembered in this connection that patients with indifferent hearing before operation were satisfied that they heard as well after operation.

The perforation healed completely in 102 out of 106 cases. A permanent perforation remained in three cases, and there A permanent perforation remained of the middle fors was no note in one. The dura of the middle age of 1 year. The lateral sinus was exposed in all but one case, year. The lateral sinus was exposed in ancisinal or extradural abscess was present in nine cases.

Temporary lasting ix all these cases the cells dipped medial to the facial canal.
There were five cases of Bezold's mastoiditis, but they did not require any further intervention beyond removal of the mastoid tip. Only one case of Gradenigo's symptom-complex was observed.

The time of healing varied from eleven to 150 days, the average being thirty-five days; plastic closure was necessary in twenty-six out of 106 cases, chiefly to prevent unsightly post-auricular depression.

The mastoid process was cellular in eighty-three cases, diploic in fourteen, sclerotic in one case (a diabetic), and there is no note in eight cases.

Blood-clot healing was the method employed in thirteen cases early in the series. The mastoid cavity, after being thoroughly cleaned by syringing and alcohol, was allowed to fill up with blood and the wound closed. Nine of these recovered without breaking down of the wound. The balance recovered after breaking down or reopening of the wound. I do not recommend this method. Within the last eighteen months fifteen cases have been drained through the post-auricular wound by means of one or more rubber tubes. The wound is closed above and below the tubes. After four days the tubes are removed painlessly and gauze packing substituted daily. By this method there is no pain during the dressings, and the results are as good as the packing method, and I believe a little quicker in healing.

Two of the 106 cases subsequently required a radical mastoid operation.

\section{MoRtality}

There were two deaths in this final series of 106 cases. Both occurred in cases of long-standing mastoiditis, which should have been operated on very much earlier Both had diploic mastoids; one died of pneumonia, and the other of cellulitis of the neck, followed by meningitis. This is not to say that I have not had other deaths following mastoid operation, but these have all been in cases where intracranial complications were present before operation, and such cases are not included in this series.

\section{Conclusion}

The main purpose of this article has been to give the results of one method of treatment of acute suppurative otitis media and its most frequent complication-acute mastoiditis. Early paracentesis is strongly indicated to prevent so far as possible the onset of mastoiditis and ensure a quick convalescence. Only 7 per cent of patients who have had an early paracentesis require a mastoid operation. Except under exceptional circumstances an acute mastoiditis does not develop for seven to twelve days after the onset of an otitis.

No attempt has been made to tabulate indications for operation, as no hard-and-fast rules can be laid down. Some patients have mastoiditis without any discharge, others with; some with swelling, others without; while tenderness and a high temperature may exist or not.

Experience counts as much here as in any other field of surgical work, and even then a furuncle may be mistaken for a mastoiditis.

\section{A Clinical Study of the Effects of Treating Malaria with Atebrin and Atebrin Musonate}

\author{
By S. F. SEELIG \\ and \\ W. SINGH
}

(From the Records of the Malaria Survey of India, Vol. VI, No. 2, June 1936, p. 171)

THIs investigation was undertaken in order to ascertain how quickly treatment of malaria patients with atebrin and atebrin musonate would restore their fitness for military duty, as judged by the clinical and parasitological effects obtained.

For this purpose, 25 patients suffering from various types of malaria were selected. These were all soldiers in the State Forces of His Highness the Maharaja of Patiala, and were treated in the Military Hospital. Patiala. The study of the clinical and parasitological observations followed closely the suggestions made by 
the Health Organization of the League of Nations. The suggested data were collected and recorded on the charts issued by the latter organization.

The total cases observed were 25 in number. They were all well fed and in excellent general condition. None could be described as being either seriously ill or suffering from any complications. None of them was a case of fresh infection, as they had all suffered from previous attacks of malaria.

TYPE OF INFECTION

\begin{tabular}{c|c|c|c}
\hline Series. & $\begin{array}{c}\text { Plasmodium } \\
\text { vivax }\end{array}$ & $\begin{array}{c}\text { Plasmodium } \\
\text { falciparum }\end{array}$ & $\begin{array}{c}\text { Plasmodium } \\
\text { malario }\end{array}$ \\
\hline I & 3 & 4 & 1 \\
II & 4 & 3 & $\ldots$ \\
III & 4 & 5 & $\ldots$ \\
1 & $\ldots$ & $\ldots$ \\
\hline
\end{tabular}

[The meaning of this table as it appears in the Records is difficult to follow. We have given our own interpretation. However, in the charts-which we have not reproduced-every case is given as a ' $\mathrm{B}$. T.' infection; this appears to be contradicted in the text. EDitor, I. M. G.]

For the purpose of treatment the patients were divided in three series as follows:-

Series I.--Eight cases received a subcutaneous injection of $0.75 \mathrm{mg}$. adrenaline $(1: 1,000)$ followed half an hour later by an intramuscular injection of $0.375 \mathrm{gm}$. atebrin musonate. Twenty-four hours later a regular peroral course was commenced with atebrin tablets, $0.1 \mathrm{gm}$. thrice daily for five subsequent days.

All cases of this group were admitted with fever, which did not appear again after the treatment was started. None of these patients showed any unusual feature which should point to a complication. Case 7 showed signs of cerebral excitation on the day of administration of atebrin musonate. However, these signs were already noticed before the injection was given. He had also vomited before treatment was commenced.

Case 4 had a slight rise of temperature due to coryza.

In none of the cases was reappearance of parasites recorded.

Series II.-The treatment in the seven cases of this series was carried out as follows:-

A dose of $0.75 \mathrm{mg}$. adrenaline $(1: 1,000)$ was injected subcutaneously, and half an hour later, this was followed by an intramuscular injection of $0.375 \mathrm{gm}$. of atebrin musonate.

All cases of this group had fever on admission and, as indicated on the charts, fever reappeared in three out of seven cases of this series. No complications or toxic symptoms were observed. Case 13 had vomited before and on the day on which treatment was commenced.

Regarding the reappearance of parasites in the blood, the same species of plasmodium as found before the commencement of treatment was detected again in case 12. The latter case also developed on the fourteenth day after commencement of the treatment a rise of temperature to a degree which necessitated a second adrenaline and atebrin musonate injection, after which no rise of temperature occurred during the following three days of observation.

Case 9 had a rise of temperature on the sixth day after the commencement of treatment. Although the blood was not examined for plasmodia on that day, a relapse may safely be assumed; adrenaline and atebrin musonate were given and the temperature became normal. On the tenth day after commencement of treatment gametocytes were found, and at once a course of plasmoquine simplex was started in doses of $0.02 \mathrm{gm}$., thrice daily, for five subsequent days. The question whether the rise of temperature on the sixth day was due to a relapse of the primary type of infection, or to gametocytes, must be left open because no parasitological record is available.

Case 10 had a rise of temperature on the fifth day after commencement of treatment. Although no parasitological record is available, a relapse was assumed and adrenaline and atebrin musonate were given. No fever and no reappearance of parasites occurred afterwards.

Case 16 showed gametocytes on the seventh day after commencement of treatment, and a regular course of plasmoquine, $0.02 \mathrm{gm}$., was given thrice daily.

In case 13 also gametocytes were found on the seventh day after treatment was commenced, and he also was given a course of plasmoquine.

The other two cases of this group presented no feature of particular interest.

Series III.-This group of nine cases was treated with two intramuscular injections of atebrin musonate, the injections being separated by an interval of 24 hours.

All the patients had fever on admission. Excepting case 24 , who had a moderate rise of temperature on the second day after the first injection, i.e., on the day following the second dose, none of them developed subsequently a temperature above normal.

Case 18 vomited on the day previous to, and on the day, when the first injection was given.

In case 17 the original species of parasites, both rings and gametocytes, were found again on the seventh day after commencement of treatment, i.e., fifth day after the second injection, although a course of plasmoquine (0.02 gm., thrice daily, for five subsequent days) was started two days after the second atebrin-musonate dose. No clinical or parasitological relapses were noticed during the following period of observation of this patient.

Neither clinical nor parasitological relapses and complications were observed in any of the other cases.

One case, case 11 , was given by mistake only one intramuscular injection of $0.375 \mathrm{gm}$. of atebrin musonate. On the seventh day after this iniection gametocytes were found, but after a course with plasmoquine they were not seen again. This patient complained of vertigo for three days. 6 th to 9 th September, 1935 , i.e., tenth to the thirteenth day after injection.

\section{Conclusions}

Twenty-five soldiers suffering from malaria, but otherwise in good general condition, were treated with different atebrin compounds. Two groups were also given injections of adrenaline in an attempt to force the parasites out of the internal organs into the general circulation, where the anti-plasmodial drug would have a better chance of acting upon them more quickly and completely.

The atebrin-musonate injection was given 30 minutes after the administration of adrenaline. This time was chosen because investigations of various authors and the experiments of one of us (S. F. S.) had previously shown that the culminating physiological general effect of adrenaline on blood pressure, pulse rate, blood sugar, circulating volume, etc., is found in normal individuals 25 to 45 minutes after the subcutaneous injection of $0.75-1 \mathrm{mg}$.

In a comparison of the effects of the three different methods of treatment under discussion, we shall have to consider the effect on

(a) the clinical condition, i.e., occurrence of clinical relapse,

(b) parasitological findings, i.e., the occurrence of parasitological relapse, and

(c) by-effects.

By comparing these different factors, it may be possible to give a fairly appropriate answer to the question of which particular method of treatment will give the best result for restoring fitness for military duty. 
Beginning with the last point, the by-effects played so small a part in our cases that they may be neglected in drawing any conclusions from this investigation.

Series I (eight cases).

(a) Effect on clinical condition and on relapse.

It appears that the method of treatment employed in this group furnished the most favourable results (adrenaline $0.75 \mathrm{mg}$ subcutaneously; atebrin musonate $0.375 \mathrm{gm}$. intramuscularly; atebrin tablets $0.1 \mathrm{gm}$. thrice daily for five days starting 24 hours after the injection of atebrin musonate)

Fever disappeared in all cases within 24 hours after the injection and did not reappear during the period of observation.

(b) As regards the parasitological findings the same favourable result was recorded.

None of the cases showed reappearance of plasmodia during the period from the commencement of treatment till the day of discharge from hospital.

Series II (seven cases).

(a) Effect on clinical condition.

The results obtained with this method (adrenaline $0.75 \mathrm{mg}$. subcutaneously and atebrin musonate $0.375 \mathrm{gm}$ intramuscularly) do not appear to be satisfactory Three out of seven cases showed a considerable rise of temperature on various days after the injections were started.

(b) The reappearance of parasites in the blood suggests the same conclusion.

In two cases parasites were found after the injection, and only two cases out of seven showed a satisfactory result after treatment.

Series III (nine cases).

(a) Effect on clinical condition.

The method employed here (two intramuscular injections of atebrin musonate $0.375 \mathrm{gm}$. separated by an interval of 24 musonate $0.375 \mathrm{gm}$. separated gave more satisfactory Series II. One case only showed fever after treatment.

(b) The same favourable result was obtained in respect of reappearance of parasites in the blood. In one case only were plasmodia found after treatment.

\section{SUMMARY}

Comparison of clinical and parasitological data permits one to conclude that the method of administering adrenaline and atebrin musonate, followed by a course with atebrin tablets, by the mouth, furnished the best results in the cases under review.

The effect on fever and parasites in blood was equally good. The patients felt quite well on the day after the injection, and, if they had not been needed for our observations, appeared fit to be discharged from hospital on that day. However, we do not wish to recommend such an early discharge, because clinical experience has proved that the 'defence forces' of the body certainly act better under conditions of complete rest in bed than under conditions of muscular and general activity. The latter necessitates a higher metabolic activity mainly supplied by the glycogen depôts of the liver. The method appears convenient for the patients because of necessitating one injection only. They could safely be discharged on the day on which the oral treatment is concluded. For practical purposes it may be possible to discharge the patient on the second or third day of atebrin treatment by mouth, recommend him for light duty, and declare him fit after three to four subsequent days in accordance with the results of blood examination.

That the physiological effects of adrenaline enhance the therapeutic action of atebrin musonate is possible, but the evidence is not conclusive.

In respect of the practical success, it can safely be stated that method I gave the best results. No clinical or parasitological relapses were detected after the commencement of treatment.

Method III gave the next best results. Only one clinical and one parasitological relapse was observed.

Method II furnished unsatisfactory results. Both clinical and parasitological relapses were more frequent than in Series. III. It appears that the dosage of $0.375 \mathrm{gm}$. atebrin musonate, although combined with adrenaline, is not sufficient.

It may be stated, therefore, that method I appears to be the safest, most reliable and convenient treatment for restoring the fitness of our patients for military duty by the administration of atebrin and atebrin musonate.

\section{Reviews}

\section{BIRCH'S MANAGEMENT AND MEDICAL TREAT- MENT MENT OF CHILDREN IN INDIA AND M.D., TROPICS.-By E. H. Vere Hodge, B.A., Edition. M.R.C.P., Lieut.-Colonel, I.M.S. Eighth Spink and 1936. Published by Messrs. Thacker, Spink and Company (1933), Limited, Calcutta. \\ 377. Illustrated. Price, Rs. 7-8}

IT is no care of children in India information regarding care of children in India informatich will be of management and medical treatment which will of this real value and assistance. The many editions of this well-known book are an indication of its success and of the widespread need which exists for a book of this type. The book was primarily intended for those without medical knowledge, out of reach of professional aid, not to replace the doctor, but to guide when he was not available, and to indicate when his presence was required. With the growth of knowledge of pædiatrics and to bring the book up to date much has now been added which is more suited to the needs of the practitioner, nurse, or medical student (in this

certain parts are marked 'for practitioners').

The first managethe tropics and the prevention of disease. The advice is essentially practical and in keeping
There is a chapter on the examination of sick children, and this is followed by descriptions of various disorders and diseases. There is a table on poisons and their treatment, a section on the administration of remedies, diets for invalids and children, a list of children's prescriptions and a table on the vitamin content of various foodstuffs.

The later editions of this book have been linked with the name of Col. Green-Armytage, and the latest edition has been brought out by his collaborator in the seventh edition, Col. Vere Hodge. The book has been almost entirely rewritten by the present author, but certain parts have been revised by other experts in special subjects, and the book contains the accumulated wisdom of many whose names are associated with the Calcutta Medical College and School of Tropical Medicine. As a handbook for nurses and practitioners in the tropics it may be recommended with the greatest confidence, but one would question whether the time has not come when the information should be presented in two volumes, one for those without medical knowledge, and the other a handbook of pædiatrics in the tropics. In the meanwhile, however, this new edition serves the double purpose better than any other book we know.

M. N. 